\title{
Temperature Effect on the Microstructures and Optical Properties of ZnO Nanowires
}

\author{
Yanglong Chen, Xianying Wang, Shufan Xie, Jian Liu, Hongbin Cheng, Xuejun Zheng, \\ Fang Liu, and Junhe Yang
}

School of Materials Science and Engineering, University of Shanghai for Science and Technology, Shanghai 200093, China

Correspondence should be addressed to Xianying Wang, xianyingwang@usst.edu.cn

Received 31 December 2011; Accepted 2 February 2012

Academic Editor: Haibo Zeng

Copyright (C) 2012 Yanglong Chen et al. This is an open access article distributed under the Creative Commons Attribution License, which permits unrestricted use, distribution, and reproduction in any medium, provided the original work is properly cited.

\begin{abstract}
Temperature effects on the microstructures and optical properties of $\mathrm{ZnO}$ nanowires were investigated extensively. Furnace calibration results showed that temperatures inside the tube furnace had Gaussian distribution. Both radial and axial growth rates of $\mathrm{ZnO}$ nanowires in the Arrhenius plot fall on straight lines. With the increase of temperatures, ZnO nanowires exhibited larger diameters, better crystal qualities, and preferred growth along $\langle 0002\rangle$ directions. Enhanced UV emission with the increase of growth temperatures was observed, while green emission was greatly reduced.
\end{abstract}

\section{Introduction}

$\mathrm{ZnO}$ nanowires (NWs) are receiving increasing interests because of their potential uses in light emitting devices (LEDs), Ultra-violet (UV) lasers, sensors, nanogenerators (NGs), and so forth [1-3]. To fabricate all kinds of $\mathrm{ZnO}$ based nanodevices, controllable synthesis of well-aligned $\mathrm{ZnO} \mathrm{NWs}$ with desirable lengths, diameters, crystal orientations is a prerequisite step. Although multiple methods have been developed, chemical vapor transport and condensation (CVTC) [4] is generally thought to be the best technique to fabricate defect and impurity-free-single crystalline $\mathrm{ZnO}$ NWs. It is very convenient to obtain vertical $\mathrm{ZnO} \mathrm{NW}$ arrays using CVTC method. However, in CVTC process, $\mathrm{ZnO}$ NWs are extremely sensitive to the experimental conditions, such as temperatures, gas flow rates, carrier gas type, $\mathrm{Zn}$ vapor rate, environmental humidity, and so forth [5]. Subtle change of the parameters, may lead to totally different morphologies. To study the effect of one condition (i.e., temperature), all the other parameters must be kept absolutely constant. Because of the diversities of the fabricating conditions, systematically studies on how these conditions affect the structural and physical properties of $\mathrm{ZnO}$ NWs remain challenging and rarely reported $[6,7]$. Temperature is the basic and most important parameter affecting the growth of $\mathrm{ZnO}$ NWs. In this work, extensive studies on the temperature effect were carried out.

\section{Experimental Description}

A tube furnace (Lindberg blue) was used to grow $\mathrm{ZnO}$ NWs via traditional CVTC method. Before growth, the temperatures of the tube furnace were carefully calibrated using a TES $1310 \mathrm{~K}$ type thermometer. 7 points with an interval of $50 \mathrm{~mm}$ were set along the tube to monitor the real temperature (Figure 1(a)). During the furnace calibration process, the furnace temperatures were set to $850^{\circ} \mathrm{C}, 900^{\circ} \mathrm{C}$, $925^{\circ} \mathrm{C}$, and $950^{\circ} \mathrm{C}$, respectively. Real temperatures at the 7 points were measured and recorded.

A-plane sapphire single crystals coated with randomly dispersed $\mathrm{Au}$ nanoparticles $(5 \mathrm{~nm})$ were used as substrates. Equal amounts of $\mathrm{ZnO}$ nanopowders (Alfa Aesar, 99.99\%) and graphite powders (Alfa Aesar, 200 mesh, 99.9\%) served as precursors to produce $\mathrm{Zn}$ vapor source. The total weight of the mixed powders was kept constant for each growth cycle to exclude any possible influences. The growth temperatures were set to $850^{\circ} \mathrm{C}, 900^{\circ} \mathrm{C}, 925^{\circ} \mathrm{C}$, and $950^{\circ} \mathrm{C}$, respectively. Other fabricating parameters are kept constant: Ar flow rate $12 \mathrm{sccm}$, growth time 10 mins, temperature ramping rate $50^{\circ} \mathrm{C} / \mathrm{mins}$. 


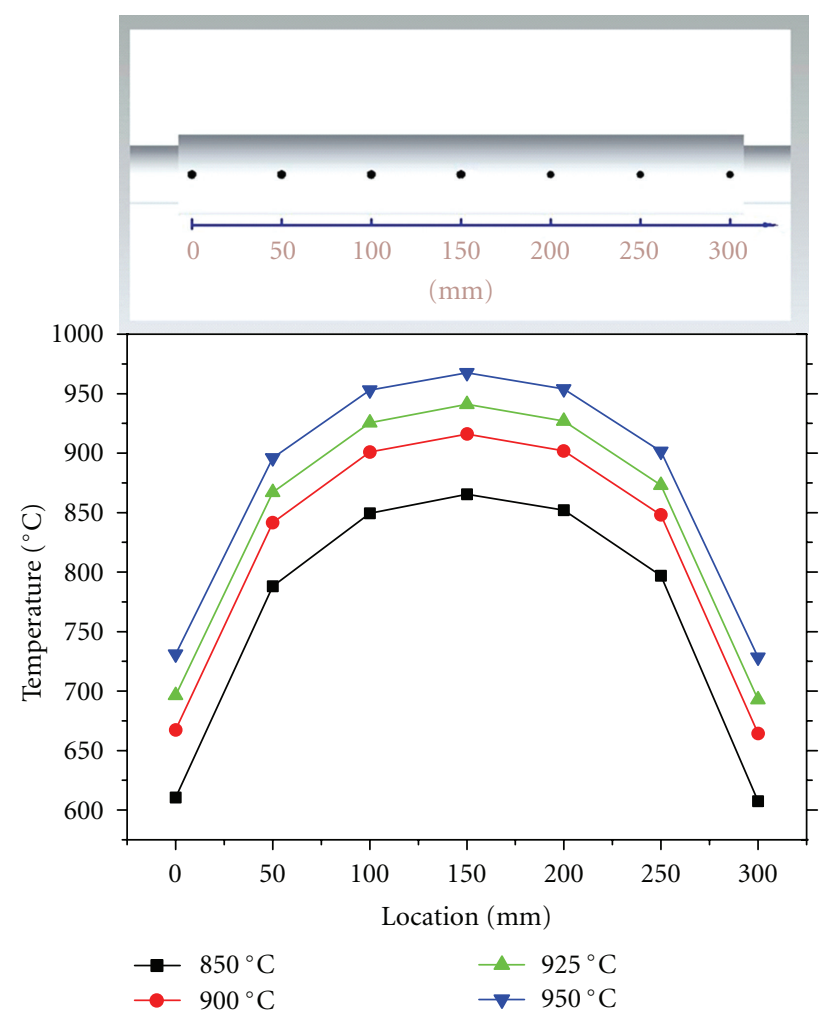

Figure 1: Furnace temperature calibration: (a) schematic diagram of the 7 test points, which were measured inside the furnace; (b) Temperature distribution curve of the furnace when displayed temperatures are $850^{\circ} \mathrm{C}, 900^{\circ} \mathrm{C}, 925^{\circ} \mathrm{C}$, and $950^{\circ} \mathrm{C}$.

The morphologies of all samples were characterized by scanning electron microscopy (SEM, FEI Quanta FEG). Room temperature photoluminescence (PL) spectra were collected using Flurolog-3-p type spectrometer in the air. The crystal structures and orientations were analyzed using X-ray diffractometry (XRD) (D8 ADVANCE, Bruker AXS).

In order to accurately control the growth temperature of $\mathrm{ZnO} \mathrm{NWs}$, the furnace temperatures at different positions must be calibrated first. As is shown in Figure 1(b), the temperatures exhibit Gaussian distributions along the furnace. The center of the tube furnace has the highest temperature (closest to the setting points). Towards two ends of the tube, temperatures decrease gradually. According to the temperature distribution curves, we can know the exact growth temperature of $\mathrm{ZnO} \mathrm{NWs}$ by monitoring the locations of substrates.

\section{Results and Discussions}

Figures 2(a)-2(d) show the SEM images of $\mathrm{ZnO} N W$ s grown under $850^{\circ} \mathrm{C}, 900^{\circ} \mathrm{C}, 925^{\circ} \mathrm{C}$, and $950^{\circ} \mathrm{C}$. As can be seen from Figure 2, with the increase of heating temperature, the diameters and lengths of NWs are distinctly various, which may be caused by the migration rates of zinc interstitials, and vacancies are largely dependent on growth temperature [8]. At the temperature of $850^{\circ} \mathrm{C}$, only sparsely dispersed short and thin nanowires were observed on the sapphire substrate and the average diameters of NWs is $40 \mathrm{~nm}$, with the length of NWs is approximately $0.83 \mu \mathrm{m}$. When the growth temperatures of $\mathrm{ZnO} N W s$ rose up to $900^{\circ} \mathrm{C} 925^{\circ} \mathrm{C}$, and $950^{\circ} \mathrm{C}$, dense vertically aligned $\mathrm{ZnO} \mathrm{NW}$ arrays can be observed. With the increase of temperature, the average diameters of $\mathrm{ZnO}$ NWs became $65 \mathrm{~nm}, 163 \mathrm{~nm}$, and $196 \mathrm{~nm}$ respectively, and the average lengths of NWs was $1 \mu \mathrm{m}$, $2.1 \mu \mathrm{m}$, and $2.9 \mu \mathrm{m}$. The increase of the diameters of $\mathrm{ZnO}$ NWs must be caused by the Oswald ripening effect of $\mathrm{Au}$ nanoparticles when annealing at high temperatures.

To understand the thermal dynamics of $\mathrm{ZnO} \mathrm{NW}$ growth, the logarithmic and radial growth rates of $\mathrm{ZnO}$ NWs as a function of the reciprocal of temperatures were plot in Figure 3. It can be seen that both the axial and radial growth rate data in Arrhenius plot fall on straight lines, indicating that all the growth was finished in reaction limited regimes. According to Arrhenius equation,

$$
k=A \exp \left(-\frac{E_{a}}{R T}\right)
$$

where $A$ is the preexponential coefficient, $E_{a}$ is the activation energy of the NW growth, $R$ is the gas constant, and $T$ is the absolute temperature. Activation energy in radical and axial direction in growth process of $\mathrm{ZnO} \mathrm{NWs}$ can be calculated. The activation energy for axial and radial $\mathrm{ZnO} \mathrm{NW}$ growth is as $E_{a x}=148.42 \mathrm{KJ}$ and $E_{r}=191.63 \mathrm{KJ}$, respectively.

Crystal structures of $\mathrm{ZnO}$ NWs fabricated under different temperatures were characterized by XRD using $\mathrm{Cu} \mathrm{Ka}$ radiation source with the wavelength of $0.154 \mathrm{~nm}$. As is shown in Figure 4, all the $\mathrm{ZnO}$ NWs show strong $\mathrm{ZnO}$ (002) 

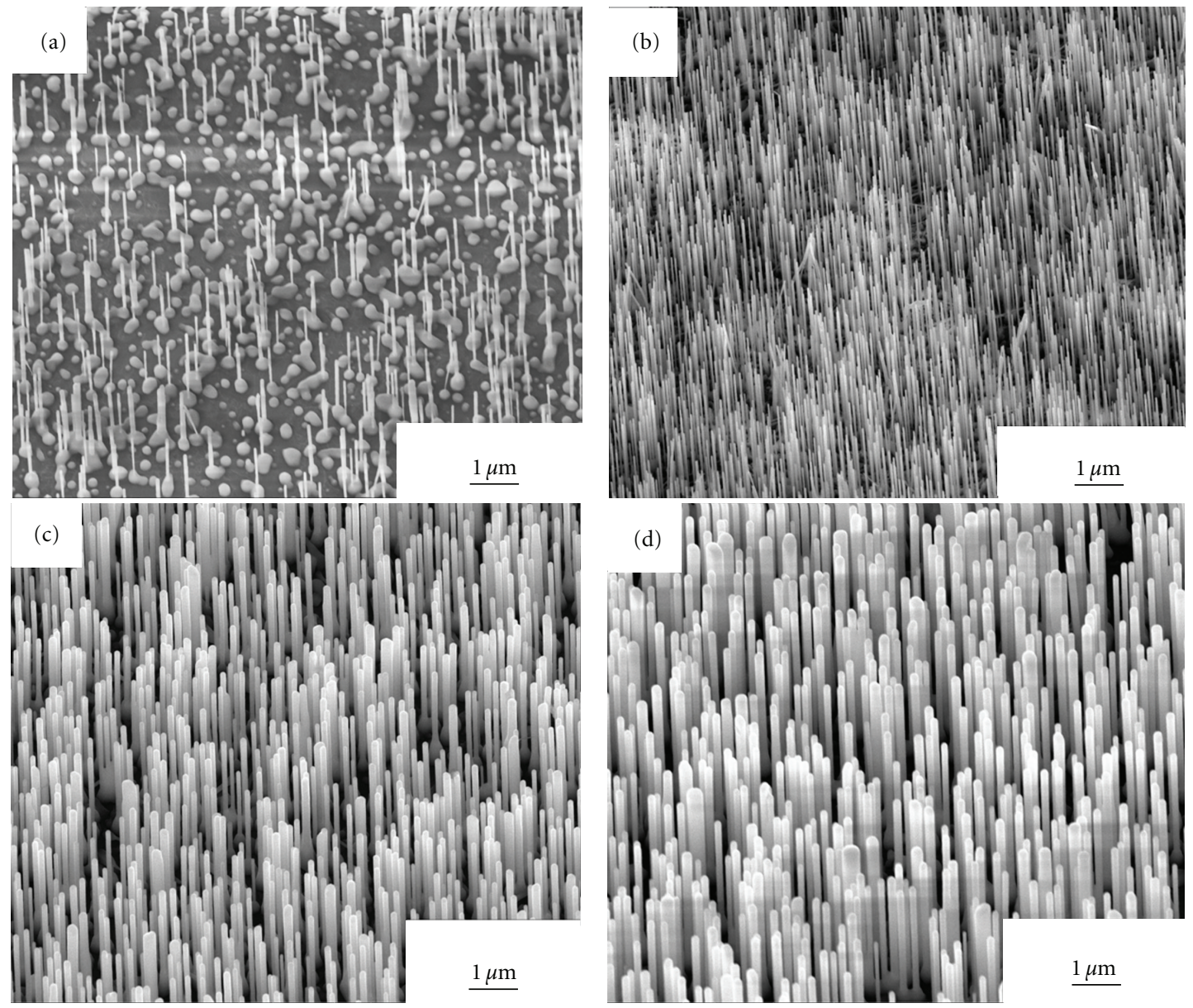

Figure 2: SEM images of ZnO NWs grown under different temperatures: (a) $850^{\circ} \mathrm{C}$, (b) $900^{\circ} \mathrm{C}$, (c) $925^{\circ} \mathrm{C}$, and (d) $925^{\circ} \mathrm{C}$.

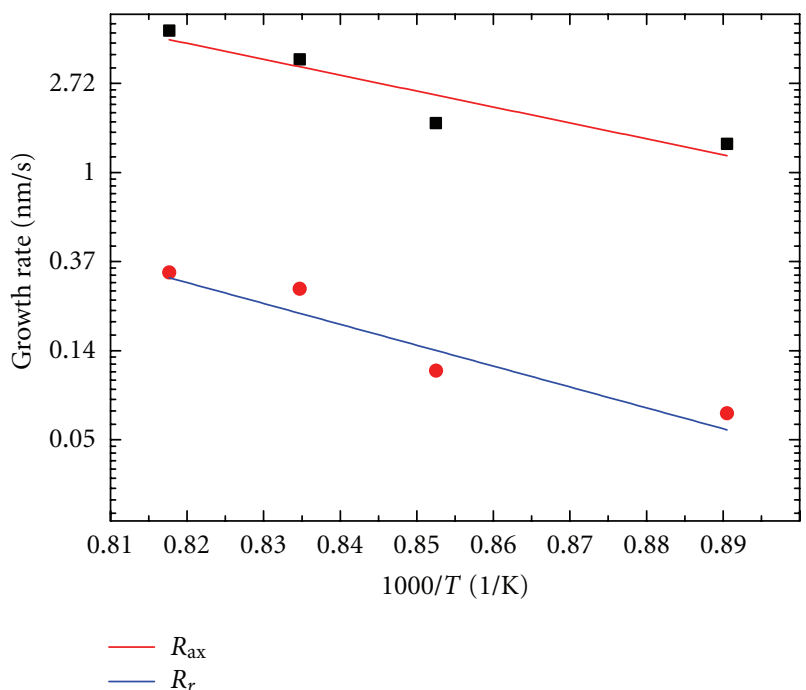

FIGURE 3: Logarithmic linear-fit line of $\mathrm{ZnO}$ NWs growth rate. Slope of line is used to calculate the activation energy along radial and axial direction. 


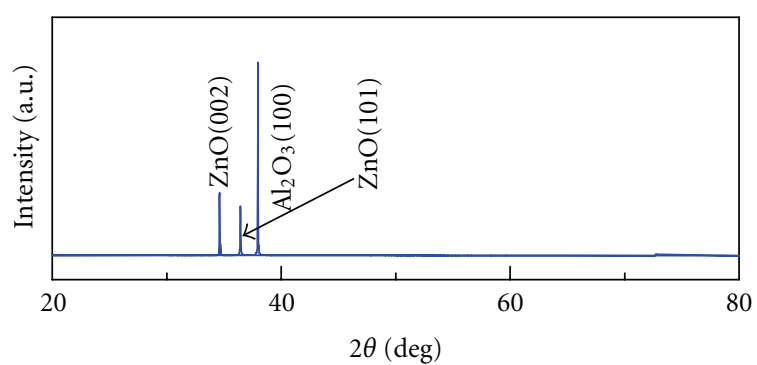

$-850^{\circ} \mathrm{C}$

(a)

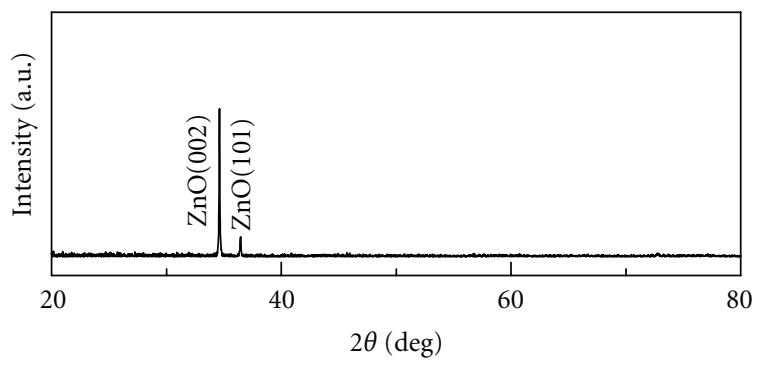

$-900^{\circ} \mathrm{C}$

(b)

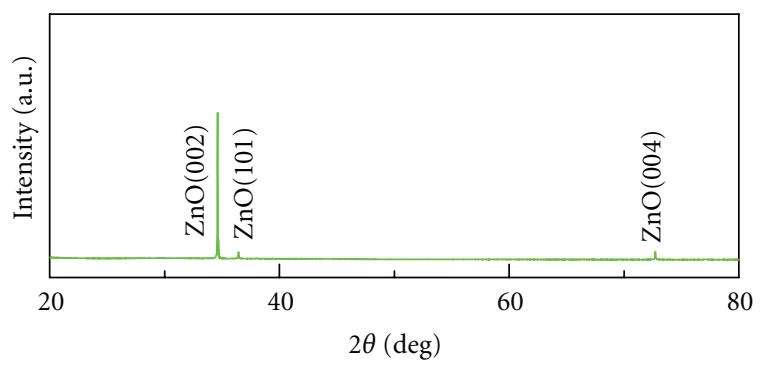

$-925^{\circ} \mathrm{C}$

(c)

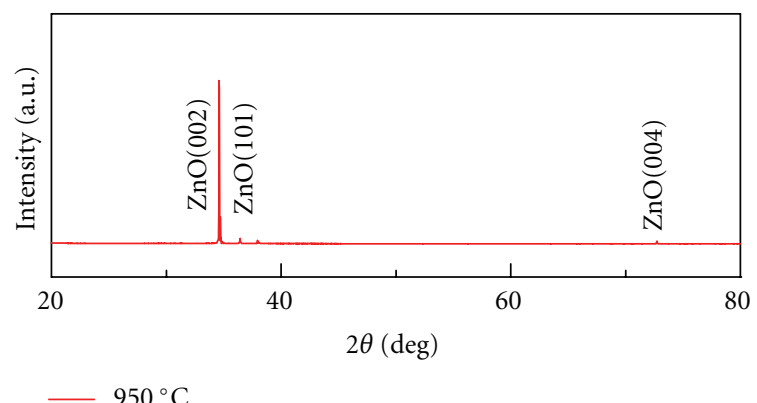

(d)

FIgURE 4: XRD spectra of $\mathrm{ZnO}$ NWs fabricated under different temperatures.

diffraction peaks, indicative of the basal plane growth mechanism. With the rising of the temperature, the relative intensity ratios of $\mathrm{ZnO}$ (002) and $\mathrm{ZnO}$ (101) peak also increase. The calculated ratio of $\mathrm{I}_{(002)}$ and $\mathrm{I}_{(101)}$ is $1.2,7.5$, $18.2,29.6$, respectively, when the growth temperature is $850^{\circ} \mathrm{C}, 900^{\circ} \mathrm{C}, 925^{\circ} \mathrm{C}$, and $950^{\circ} \mathrm{C}$. It implied that crystal

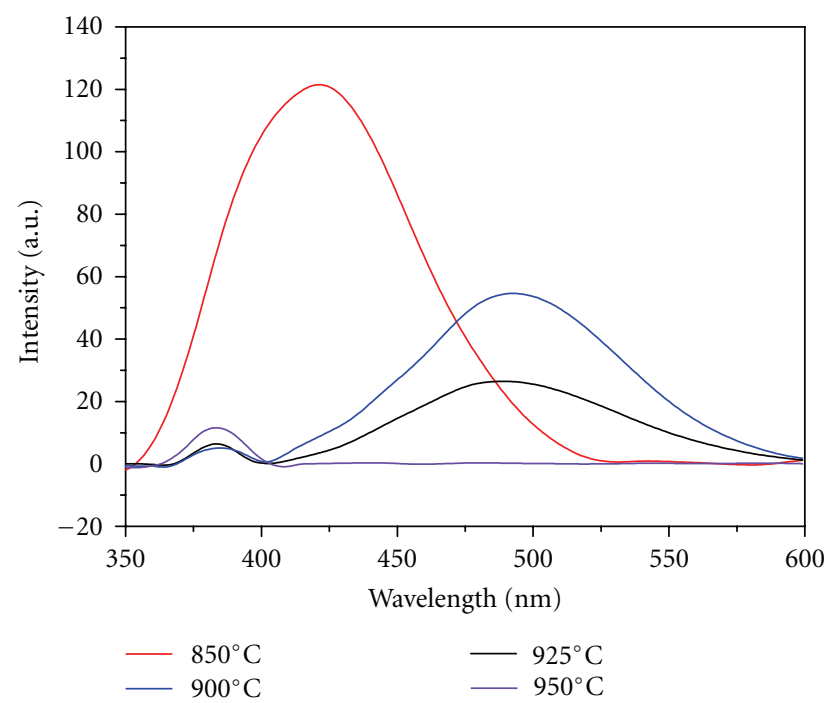

FIGURE 5: Room temperature photoluminescence spectra of $\mathrm{ZnO}$ NWs array grown on alumina substrate under different temperatures.

quality of $\mathrm{ZnO} \mathrm{NWs}$ was improved and $c$-axis growth is preferred with the increase of heating temperatures. Only $\mathrm{Al}_{2} \mathrm{O}_{3}$ (100) diffraction peak was observed when the growth temperature is $850^{\circ} \mathrm{C}$ due to the low density of NWs, which is corresponding to the SEM images in Figure 2(a).

To study the optical properties of $\mathrm{ZnO}$ NWs, room temperature PL spectra were tested using He-Cd laser with a wavelength of $325 \mathrm{~nm}$ as the excitation light. Figure 5 presents the PL spectra of $\mathrm{ZnO}$ NWs fabricated under different temperatures. When the growth temperature is $850^{\circ} \mathrm{C}$, only a broad peak centered at $420 \mathrm{~nm}$ can be observed, which might be caused by the sapphire substrate. At the growth temperatures of $900^{\circ} \mathrm{C}, 925^{\circ} \mathrm{C}$, and $950^{\circ} \mathrm{C}$, bandedge emission in the UV region and green emission can be observed. It is appreciable that PL peak intensity in the green region decreases with the increase of the NW growth temperatures. It is generally thought that the green band emission of $\mathrm{ZnO}$ NWs is from recombination of photon-generated hole with an electron generated from an ionized oxygen vacancy $[9,10]$. Higher growth temperature leads to $\mathrm{ZnO}$ NWs with larger diameters, which reduces the surface states and oxygen vacancies and results in the weak green light emission. When the growth temperature is $950^{\circ} \mathrm{C}$, the green emission is very weak and only the UV emission centered around $380 \mathrm{~nm}$ can be observed, indicating high crystal quality at this growth temperature.

\section{Conclusions}

In summary, temperature effects on the microstructures and optical properties of $\mathrm{ZnO}$ NWs array were studied. By precisely controlling the local temperatures of the tube furnace, NWs were grown under different temperatures through traditional CVTC process. Morphology analysis showed that lengths and diameters of $\mathrm{ZnO}$ NWs increase with the rising 
of temperatures. The growth rates as a function of the reciprocal of temperatures were studied, and the results indicated that the growth of $\mathrm{ZnO}$ NWs were in the reaction limited regimes. XRD studies illustrated that higher temperatures could lead to better crystal quality and favor basal growth mechanism. Optical property investigations indicated that higher growth temperature would weak the green light emission, indicative of reduced defects and oxygen vacancies. These results collectively suggest that higher temperatures are preferred to get $\mathrm{ZnO}$ NWs with better crystal qualities.

\section{Acknowledgments}

This paper is financially supported by NNSF (51072119, 10825209), Shanghai Nano (1052 nm03000,11 nm 0502600), STCSM (10231201103), Innovation Program of Shanghai Municipal Education Commission (12ZZ139), Changjiang Scholar Incentive Program ([2009] 17), and open research program of shanghai key laboratory of modern metallurgy and materials processing.

\section{References}

[1] A. Kumar, H. Gullapalli, K. Balakrishnan et al., "Flexible ZnOcellulose nanocomposite for multisource energy conversion," Small, vol. 7, no. 15, pp. 2173-2178, 2011.

[2] X. Wang, J. Zhou, J. Song, J. Liu, N. Xu, and Z. L. Wang, "Piezoelectric field effect transistor and nanoforce sensor based on a single ZnO nanowire," Nano Letters, vol. 6, no. 12, pp. 2768-2772, 2006.

[3] S. Chu, M. Olmedo, Z. Yang, J. Kong, and J. Liu, "Electrically pumped ultraviolet $\mathrm{ZnO}$ diode lasers on Si," Applied Physics Letters, vol. 93, no. 18, Article ID 181106, 2008.

[4] P. Yang, H. Yan, S. Mao et al., "Controlled growth of $\mathrm{ZnO}$ nanowires and their optical properties," Advanced Functional Materials, vol. 12, no. 5, pp. 323-331, 2002.

[5] M. H. Huang, Y. Wu, H. Feick, N. Tran, E. Weber, and P. Yang, "Catalytic growth of zinc oxide nanowires by vapor transport," Advanced Materials, vol. 13, no. 2, pp. 113-116, 2001.

[6] C. Liu, J. A. Zapien, Y. Yao et al., "High-density, ordered ultraviolet light-emitting $\mathrm{ZnO}$ nanowire arrays," Advanced Materials, vol. 15, no. 10, pp. 838-841, 2003.

[7] E. C. Greyson, Y. Babayan, and T. W. Odom, "Directed growth of ordered arrays of small-diameter $\mathrm{ZnO}$ nanowires," Advanced Materials, vol. 16, no. 15, pp. 1348-1352, 2004.

[8] S. Rackauskas, A. G. Nasibulin, H. Jiang et al., "Mechanistic investigation of $\mathrm{ZnO}$ nanowire growth," Applied Physics Letters, vol. 95, no. 18, Article ID 183114, 3 pages, 2009.

[9] Z. Fan, P. C. Chang, J. G. Lu et al., "Photoluminescence and polarized photodetection of single $\mathrm{ZnO}$ nanowires," Applied Physics Letters, vol. 85, no. 25, pp. 6128-6130, 2004.

[10] H. Zeng, G. Duan, Y. Li, S. Yang, X. Xu, and W. Cai, "Blue luminescence of $\mathrm{ZnO}$ nanoparticles based on non-equilibrium processes: defect origins and emission controls," Advanced Functional Materials, vol. 20, no. 4, pp. 561-572, 2010. 

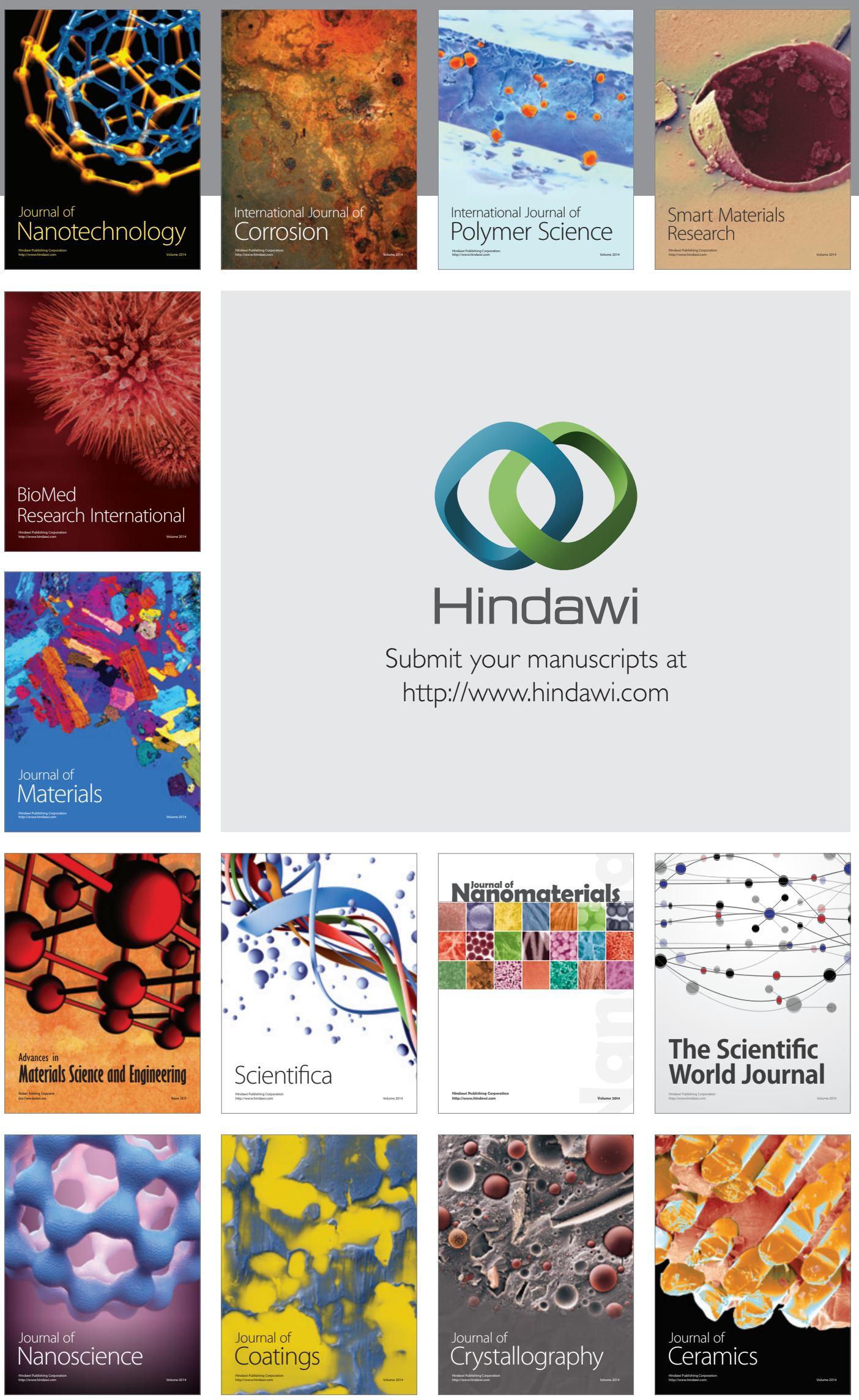

The Scientific World Journal

Submit your manuscripts at

http://www.hindawi.com

\section{World Journal}

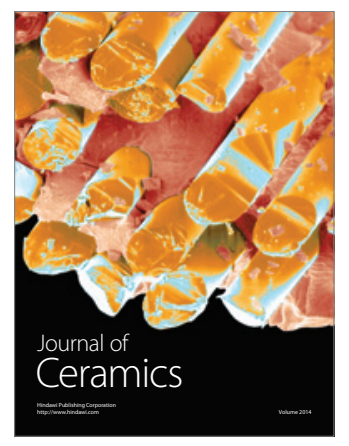

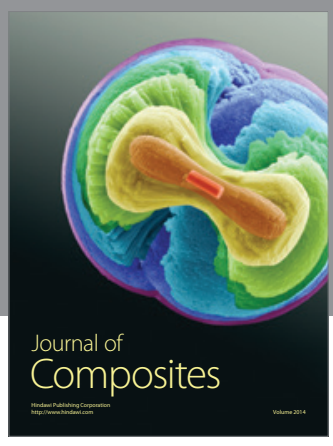
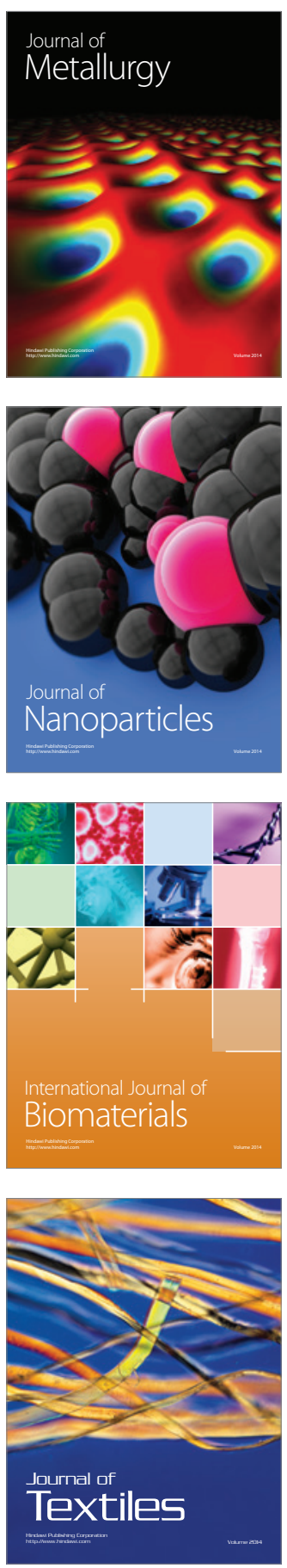